\title{
Requirement for T Cells and Effect of Lymphokines in Successful Chemotherapy for an Intracellular Infection
}

\author{
Experimental Visceral Leishmaniasis
}

Henry W. Murray, Melissa J. Oca, Angela M. Granger, and Robert D. Schreiber*

Division of Infectious Diseases, Cornell University Medical College, New York 10021; and *Department of Pathology, Washington University School of Medicine, St. Louis, Missouri 63110

\begin{abstract}
Although directly microbicidal, pentavalent antimony has failed as treatment for visceral leishmaniasis in patients who also have AIDS or are receiving immunosuppressive therapy. To define the role of $T$ cells in the successful host response to chemotherapy, we examined the efficacy of pentavalent antimony (sodium stibogluconate, Pentostam) in normal and $T$ cell-deficient BALB/c mice infected with Leishmania donovani. In euthymic (nu/+) mice, single injections of 250 and 500 $\mathrm{mg} / \mathrm{kg}$ of Pentostam induced the killing of $67 \%$ and $89 \%$ of intracellular liver amastigotes, respectively. In contrast, in athymic nude (nu/nu) mice, up to three injections of $500 \mathrm{mg} / \mathrm{kg}$ achieved no $L$. donovani killing and did not retard visceral parasite replication. Once nude mice were reconstituted with nu/+ spleen cells, however, Pentostam exerted strong leishmanicidal activity, an effect that appeared to be transferred by either $\mathrm{L3T4}^{+}$or $\mathrm{Lyt}^{+}{ }^{+}$cells. Responsiveness to chemotherapy could also be induced by providing nude mice with either interferon- $\gamma$ or interleukin 2 alone. The absence of this $T$ cell- and probably lymphokine-dependent mechanism is a likely explanation for treatment failures in immunocompromised patients infected with $L$. donovani and perhaps other systemic intracellular pathogens as well.
\end{abstract}

\section{Introduction}

Despite the use of chemotherapeutic agents with direct microbicidal activity, treatment failures are nevertheless regularly encountered in patients with quantitative or functional $T$ cell defects who develop opportunistic intracellular infections. Clinical experience in patients with the acquired immunodeficiency syndrome (AIDS) has graphically magnified these diffculties, and served to reemphasize the long-held assumption that control over such infections also requires an intact cellmediated immune response.

Recent reports have indicated that spontaneously controlled (subclinical) infections caused by the intracellular protozoan, Leishmania donovani, may reactivate in immunocompromised patients (1-7). In addition, primary treatment

Address reprint requests to Dr. Murray, Division of Infectious Diseases, Cornell University Medical College, 1300 York Avenue, New York, NY 10021.

Received for publication 27 May 1988 and in revised form $18 \mathrm{No}$ vember 1988.

J. Clin. Invest.

(c) The American Society for Clinical Investigation, Inc.

0021-9738/89/04/1253/05 \$2.00

Volume 83, April 1989, 1253-1257 failures using ordinarily effective pentavalent antimony (e.g., sodium stibogluconate, or Pentostam [proprietary name of Burroughs Wellcome]) as well as prompt relapses have also been described in Leishmania donovani-infected patients who have AIDS or are receiving immunosuppressive agents (5-7). Since successful host resistance in visceral leishmaniasis is $\mathrm{T}$ cell dependent (8-10) and probably mediated by macrophages activated by $\mathrm{T}$ cell-derived lymphokines (e.g., interferon- $\gamma$ [IFN- $\gamma$ ]) (9-19), neither the preceding clinical observations nor the designation of $L$. donovani as an opportunistic pathogen are surprising.

However, considering visceral leishmaniasis treated with Pentostam as a model, three other observations suggest that the reasons why $T$ cell-deficient patients may fail to respond to appropriate antimicrobial therapy are more complex. First, Pentostam is known to exert direct microbicidal activity against intracellular $L$. donovani, and in vitro, does not require either $\mathrm{T}$ cells or activating lymphokines to achieve this effect $(20,21)$. Secondly, despite the typical absence of either delayed-type hypersensitivity reactions or in vitro $\mathrm{T}$ cell reactivity to specific leishmanial antigen $(8,18,19,22)$, most otherwise healthy patients with visceral leishmaniasis respond well to pentavalent antimony treatment $(23,24)$. Thirdly and similarly, at a time when their $\mathrm{T}$ cells show no detectable responsiveness to leishmanial antigen (e.g., no proliferative activity or lymphokine secretion $[9,12]), L$. donovani-infected euthymic mice readily respond to Pentostam with a rapid decrease in visceral parasite burdens (21).

To test the hypothesis that host T cell activity, albeit "undetectable," is nevertheless required for a successful response to therapy for an intracellular infection, we examined Pentostam treatment for visceral leishmaniasis in nude (athymic) mice before and after reconstitution with either $\mathrm{T}$ cells or recombinant $(r)^{1} T$ cell lymphokines. In this model of the $T$ cell-deficient host, our results demonstrate that the efficacy of antimicrobial chemotherapy is strictly $T$ cell dependent and can be enhanced by IFN- $\gamma$ and interleukin 2 (IL-2).

\section{Methods}

Mice, in vivo infection, and treatment. Congenitally athymic nude (nu/nu) 20-30-g female mice bred on a BALB/c background and their euthymic $(\mathrm{nu} /+)$ littermates were purchased from Life Sciences (St. Petersburg, FL), and maintained under similar conventional conditions. To establish infection, mice were injected by tail vein with $0.2 \mathrm{ml}$ of infected hamster spleen homogenate containing $1 \times 10^{7} \mathrm{~L}$. donovani amastigotes (one Sudan strain) $(9,12)$. The level of visceral infection was determined by examining Giemsa-stained liver imprints and mi-

1. Abbreviations used in this paper: IP, intraperitoneal; LDU, Leishman-Donovan unit; $r$, recombinant. 
croscopically quantitating hepatic parasite burdens as Leishman-Donovan units (LDUs) $(9,12) .2$ wk after infection (day 0$)$, when mice were heavily parasitized $(9,12)$, groups of three mice were treated with intraperitoneal (IP) injections of sodium stibogluconate (Pentostam, Burroughs Wellcome Co., Research Triangle Park, NC) (21). Liver parasite burdens were determined on day $+7,1$ wk after the initiation of therapy (21). Amastigote killing was calculated by comparing day +7 LDUs in treated mice to day 0 LDUs in untreated control mice; inhibition of parasite replication was determined by comparing day +7 LDUs in treated mice to day +7 LDUs in untreated control mice (21). Differences were analyzed by a two-tailed $t$ test for independent samples.

In vivo reconstitution with spleen cells. $1 \mathrm{~d}$ before $L$. donovani infection, nude mice received by tail vein $1 \times 10^{7}$ spleen cells obtained from either uninfected nu/+ mice or immune nu/+ mice which had resolved a prior $L$. donovani infection $(9,10)$. The spleen cells transferred were unfractionated or were first depleted by $>85 \%$ of either L3T $4^{+}$or Lyt- $2^{+}$cells using a standard negative-selection technique (10). The latter employed anti-L3T4 and anti-Lyt-2 monoclonal antibodies derived from culture supernatants of the GK 1.5 and TIB 105 hybridoma cell lines (American Type Culture Collection, Rockville, MD), respectively, and complement treatment (10).

In vivo reconstitution with recombinant lymphokines. Infected nude mice were treated before and after Pentostam with four IP injections of $10^{5} \mathrm{U}$ of human rIL-2 (E. coli-derived, $2 \times 10^{7} \mathrm{U} / \mathrm{mg}$ of protein, Hoffmann-La Roche Inc., Nutley, NJ) or $10^{5} \mathrm{U}$ of murine rIFN- $\gamma\left(E\right.$. coli-derived, $1.9 \times 10^{7} \mathrm{U} / \mathrm{mg}$ of protein, Genentech, Inc., South San Francisco, CA) (9). A single dose of IP Pentostam was given after 2 wk of infection (day 0 ), and injections of rIL-2 or rIFN- $\gamma$ were administered twice before (days -2 and -1 ) and twice after Pentostam (days +3 and +4$)(9,21)$. rIL-2 and rIFN- $\gamma$ were diluted in saline containing $1 \mathrm{mg} / \mathrm{ml}$ of bovine serum albumin (BSA) and injected in a volume of $0.2 \mathrm{ml}$. Control mice received BSA alone.

In vivo depletion of $\mathrm{LSTH}^{+}$and $\mathrm{Lyt}-2^{+}$cells. Euthymic $(\mathrm{nu} /+)$ mice were treated once a day for $5 \mathrm{~d}$ prior to $L$. donovani challenge with IP injections of $1 \mathrm{ml}$ of the GK 1.5 and TIB 105 hybridoma culture supernatants. Parallel experiments demonstrated that this treatment depleted the appropriate spleen T cell subset by $\geq 90 \%$ (10). After $L$. donovani infection, mice received thrice-weekly $1-\mathrm{ml}$ injections of antibody (10) during the $2 \mathrm{wk}$ before and the $1 \mathrm{wk}$ after single-dose Pentostam treatment.

In vitro activity of Pentostam. Resident peritoneal macrophages were obtained from nu/ + and nude mice, cultivated overnight on $12-\mathrm{mm}$ round glass coverslips, and then challenged with $5 \times 10^{6} \mathrm{~L}$. donovani amastigotes (12). After $1 \mathrm{~h}$ (time zero), uningested parasites were removed by washing, and cells were reincubated at $37^{\circ} \mathrm{C}$ in $5 \%$ $\mathrm{CO}_{2}-95 \%$ air in tissue culture medium containing $20 \mu \mathrm{g} / \mathrm{ml}$ of Pentos$\operatorname{tam}(21) .48 \mathrm{~h}$ later, duplicate coverslips were fixed and stained, and intracellular killing was assessed by counting the number of amastigotes per 100 cells present at time zero and at $48 \mathrm{~h} \mathrm{(21).}$

\section{Results}

In vivo efficacy of Pentostam. 2 wk after L. donovani challenge, liver parasite burdens in both euthymic $(\mathrm{nu} /+)$ and nude mice increase logarithmically $(9,12,21)$, spleen cells from both types of mice do not secrete detectable levels of IFN- $\gamma$ or IL-2 upon in vitro stimulation with leishmanial antigen (9), and IFN- $\gamma$ is not measurable in the serum of normal animals $(K$. Squires, R. Schreiber, and H. Murray, unpublished observations). At this time in euthymic mice, single injections of Pentostam achieved two dose-dependent effects (Fig. 1): inhibition of visceral parasite replication at $100 \mathrm{mg} / \mathrm{kg}$, and $70-90 \%$ killing at 250 and $500 \mathrm{mg} / \mathrm{kg}(21)$. In contrast, in nude mice, treatment with up to $500 \mathrm{mg} / \mathrm{kg}$ of Pentostam failed to achieve any discernible antileishmanial effect. Treatment failure was

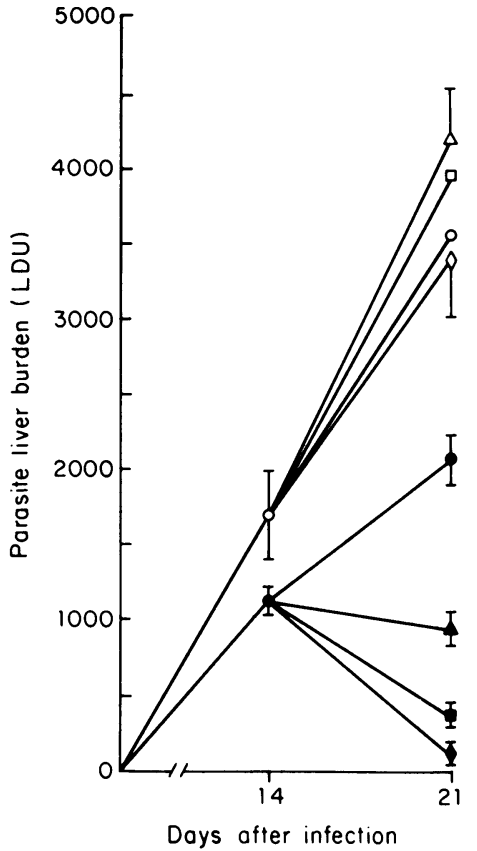

not due to suboptimal dosing; nude mice treated for $1 \mathrm{wk}$ with three injections of $500 \mathrm{mg} / \mathrm{kg}$ every other day still showed no antileishmanial response (three experiments, data not shown).

In vitro efficacy of Pentostam. To examine a possible defect in nude mice in the interaction of Pentostam with its target cell, peritoneal macrophages were infected in vitro and treated with a microbicidal concentration of Pentostam. After $48 \mathrm{~h}$ of exposure to $20 \mu \mathrm{g} / \mathrm{ml}(21), \geq 69 \%$ of intracellular amastigotes were killed by all macrophages tested including cells from uninfected and 2-wk infected euthymic and nude mice (two experiments, not shown). Thus, nude mice did not appear to display a defect at the level of macrophage-Pentostam interaction.

Restoration of responsiveness to Pentostam by $T$ cell reconstitution. To determine the role of $\mathrm{T}$ cells in permitting Pentostam to exert its antileishmanial activity, nude mice were reconstituted with spleen cells obtained from either normal uninfected $\mathrm{nu} /+$ or immune nu/+ mice (10). The latter resist rechallenge with $L$. donovani $(9,25)$, and their Thy $-1^{+}$spleen cells, which respond to leishmanial antigen with the secretion of IFN- $\gamma$ and IL 2 (9), can transfer resistance to naive animals $(10,25)$. As shown in Table I, once reconstituted with unfractionated nu/+ cells, nude mice readily acquired the capacity to respond to single-dose Pentostam treatment with both leishmanistatic $(100 \mathrm{mg} / \mathrm{kg})$ and leishmanicidal activity $(500$ $\mathrm{mg} / \mathrm{kg}$ ). Unfractionated spleen cells from uninfected $\mathrm{nu} /+$ mice were as effective as cells from immune mice indicating that prior antigen sensitization was not required to achieve these results.

Role of $\mathrm{L3T4}^{+}$and $\mathrm{Lyt}-2^{+}$cells. To identify the $\mathrm{T}$ cell subset apparently responsible for establishing the ability to respond to chemotherapy, two approaches were used. First, immune spleen cells were depleted of either $\mathrm{L} 3 \mathrm{~T}_{4}^{+}$and Lyt- $2^{+}$ cells before transfer into nude mice, and secondly, euthymic $(\mathrm{nu} /+)$ mice were injected with monoclonal antibodies which deplete these cells in vivo (10). The data in Table I indicate that for nude mice, responsiveness to Pentostam could be comparably induced by the transfer of cells depleted of either 
Table I. Response to Pentostam in Reconstituted Nude Mice

\begin{tabular}{ccccc}
\hline & \multicolumn{4}{c}{ Parasite liver burdens on day 7: cells transferred } \\
\cline { 2 - 5 } Pentostam & None & Unfractionated & $\begin{array}{c}\text { Anti-Lyt-2+ } \\
\text { treated }\end{array}$ & $\begin{array}{c}\text { Anti-L3T4 } \\
\text { treated }\end{array}$ \\
\hline Normal cells & & & & \\
0 (saline) & $3,988 \pm 189$ & $3,324 \pm 126$ & $\mathrm{ND}^{*}$ & $\mathrm{ND}$ \\
$100 \mathrm{mg} / \mathrm{kg}$ & $3,625 \pm 142$ & $1,579 \pm 87$ & $\mathrm{ND}$ & $\mathrm{ND}$ \\
$500 \mathrm{mg} / \mathrm{kg}$ & $3,503 \pm 129$ & $642 \pm 66$ & $\mathrm{ND}$ & $\mathrm{ND}$ \\
Immune cells & & & & \\
$0(\mathrm{saline})$ & $2,498 \pm 162$ & $2,779 \pm 108$ & $2,380 \pm 118$ & $2,849 \pm 183$ \\
$100 \mathrm{mg} / \mathrm{kg}$ & $2,113 \pm 94$ & $1,419 \pm 189$ & $1,031 \pm 148$ & $1,301 \pm 43$ \\
$500 \mathrm{mg} / \mathrm{kg}$ & $1,983 \pm 121$ & $306 \pm 102$ & $677 \pm 112$ & $446 \pm 68$ \\
& & & & \\
\hline
\end{tabular}

$1 \mathrm{~d}$ before $L$. donovani challenge, $1 \times 10^{7}$ unfractionated normal or immune nu/+ spleen cells or immune spleen cells depleted of either $\mathrm{L} 3 \mathrm{~T}^{+}{ }^{+}$or Lyt $-2^{+}$cells were transferred into nude mice. $2 \mathrm{wk}$ later (day 0), groups of three mice received a single injection of saline or Pentostam, and liver parasite burdens were determined $7 \mathrm{~d}$ later. On day 0, mean LDUs of control and reconstituted mice were similar and ranged from $1,199 \pm 52$ to $1,323 \pm 81$. Results shown are from one experiment representative of two performed with normal spleen cells and three performed with immune cells, and indicate mean \pm SEM LDU for three mice.

* ND, not done.

T cell subset. Similarly, for euthymic mice, in vivo depletion of one $\mathrm{T}$ cell subset or the other did not affect responsiveness to Pentostam (three experiments, data not shown). Since the transfer of resistance to $L$. donovani in this model is dependent on Thy- $1^{+} \mathrm{T}$ cells (25), both of the preceeding results suggest that $\mathrm{L} 3 \mathrm{~T}^{+}$and $\mathrm{Lyt}-2^{+}$cells can probably mediate the in vivo expression of antileishmanial chemotherapy. These results do not, however, formally exclude the unlikely possibility that other cells such as B cells or natural killer cells also play some role.

Effect of IFN- $\gamma$ and IL 2. Although otherwise healthy patients with visceral leishmaniasis and euthymic mice acutely infected with $L$. donovani typically respond to Pentostam, their peripheral blood mononuclear cells or spleen cells, respectively, fail to respond to leishmanial antigen with the secretion of IL- 2 and IFN- $\gamma(9,18,19)$. Since IFN- $\gamma$ and IL 2 , key macrophage- and $\mathrm{T}$ cell-activating lymphokines (11), may nevertheless still be produced in vivo (presumably within the microenvironment of the infected tissue granuloma [9]), we completed this analysis by providing nude mice with these lymphokines before and after Pentostam injection. Using doses and schedules employed in prior studies in euthymic mice $(9,17,21)$, treatment of nude mice with either rIFN- $\gamma$ or rIL-2 partially restored responsiveness to Pentostam (Table II). The beneficial effects of these lymphokines were observed using high-dose Pentostam $(500 \mathrm{mg} / \mathrm{kg})$, and while associated with only moderate microbicidal activity, permitted the expression of pronounced Pentostam-induced leishmanistatic activity.

\section{Discussion}

This study was initiated to explore the question of why $T$ cell-deficient patients with intracellular infections may fail to respond to appropriate microbicidal antibiotic therapy. The
Table II. Effect of IFN- $\gamma$ and IL-2 Treatment on Response to Pentostam in Nude Mice

\begin{tabular}{lcc}
\hline & \multicolumn{2}{c}{ Liver burden on day 7} \\
\cline { 2 - 3 } \multicolumn{1}{c}{ Treatment } & $\begin{array}{c}\text { IFN- } \gamma \\
\text { (day } 0=1,193 \pm 105)\end{array}$ & $\begin{array}{c}\text { IL-2 } \\
\text { (day } 0=1,457 \pm 75)\end{array}$ \\
\hline None (control) & $2,898 \pm 106$ & $3,964 \pm 231$ \\
Pentostam 100 & $3,302 \pm 158$ & $3,856 \pm 190$ \\
$\quad 500$ & $2,652 \pm 189$ & $3,521 \pm 135$ \\
BSA alone & $2,980 \pm 202$ & $4,012 \pm 154$ \\
Lymphokines alone & $3,244 \pm 130$ & $3,583 \pm 214$ \\
Lymphokines + Pentostam 100 & & \\
$\quad+$ lymphokines & $2,903 \pm 89$ & $3,236 \pm 192$ \\
BSA + Pentostam 100 + BSA & $3,126 \pm 142$ & $3,912 \pm 148$ \\
Lymphokines + Pentostam 500 & & \\
$\quad+$ lymphokines & $621 \pm 123^{*}$ & $1,026 \pm 188^{*}$ \\
BSA + Pentostam 500 + BSA & $3,010 \pm 78$ & $3,419 \pm 102$ \\
\end{tabular}

2 wk after infection (day 0 ), nude mice (three or four mice per group) were treated with either 100 or $500 \mathrm{mg} / \mathrm{kg}$ of Pentostam, and liver burdens (LDU) were determined 1 wk later (day +7). BSA and lymphokines, $10^{5} \mathrm{U}$ of rIFN- $\gamma$ or rIL-2, were injected on days -2 , $-1,+3$, and +4 (21), and saline or Pentostam was injected on day 0 . Mean day $0 \mathrm{LDU}$ for all groups were within $12 \%$ of the day $0 \mathrm{LDU}$ value shown for the controls. Results summarize data from three separate experiments using IFN- $\gamma$ and three experiments using IL-2, and indicate mean \pm SEM LDU for a total of 9-12 mice per group (IFN- $\gamma$ ) or 9 mice per group (IL-2).

* Compared to day 7 LDU for control mice, day 7 IFN- $\gamma$ and day 7 IL-2 results indicate $79 \%$ and $74 \%$ inhibition of replication of $L$. donovani, respectively $(P<0.02)$. Day $7 \mathrm{LDU}$ results for treated mice were not significantly different $(P>0.05)$ from day 0 LDU of control mice.

specific question addressed was why, if a chemotherapeutic agent such as Pentostam is both directly microbicidal towards intracellular $L$. donovani in vitro $(20,21)$ and effective in healthy $L$. donovani-infected patients and animals whose $\mathrm{T}$ cells show no specific immunologic reactivity $(9,18,19,22)$, should it fail in immunosuppressed patients or T cell-deficient individuals with AIDS (5-7)? As judged by this analysis, the best answer appears to be that while antigen-specific $T$ cell reactivity may not be detectable in the Pentostam-responsive host (using current in vitro assays), functional $T$ cells are nonetheless strictly required for a successful in vivo response to chemotherapy. This latter finding probably explains treatment failures in $L$. donovani-infected patients who have AIDS or are receiving therapy directed at suppressing $\mathrm{T}$ cell function (5-7). Whether our observations are also relevant to treatment failures and the propensity for relapse in patients with visceral leishmaniasis in certain parts of the world (e.g., Kenya [22-24]) remains to be determined.

We were not surprised to find that both $\mathrm{L}_{3} 4^{+}$(helper) and Lyt- $2^{+}$(cytotoxic) cells appeared capable of mediating in vivo responsiveness to Pentostam or that $\mathrm{T}$ cell-derived lymphokines may play important roles. In a previous study, for example, we demonstrated that acquired resistance to $L$. donovani and effective control over visceral parasite replication requires both $\mathrm{L} \mathrm{T}^{+}{ }^{+}$and $\mathrm{Lyt}-2^{+}$cells (10). In addition, both subsets rapidly populate and are necessary for the functional development of the tissue granuloma provoked by $L$. donovani-para- 
sitized macrophages (26). The primary role of the sensitized $\mathrm{L} \mathrm{T}_{4}{ }^{+}$cell in this mechanism is likely to be antigen-triggered secretion of the $\mathrm{T}$ cell-activating lymphokine, IL-2, and in particular, the production of the macrophage-activating lymphokine, IFN- $\gamma(10)$. The sensitized Lyt- $2^{+}$cell, perhaps stimulated by IL-2 (27), may act in a cytotoxic fashion towards parasitized macrophages (28), but in addition, can also secrete activating lymphokines including IFN- $\gamma(10)$.

Although our experiments were not intended to define the optimal doses or regimens for treating nude mice with IL-2 and IFN- $\gamma$, the results indicated that both lymphokines by themselves could act in vivo to allow expression of Pentostam's antileishmanial activity. While it is possible that more intensive treatment with IFN- $\gamma$ (29) or IL-2 might have better mimicked the effects of cellular reconstitution and permitted Pentostam's leishmanicidal activity to become more evident, preliminary studies in infected nude mice suggest that functional $\mathrm{T}$ cells may also be required for optimal in vivo responsiveness to IFN- $\gamma$ (H. Murray, unpublished observations).

In addition to directly activating macrophages to kill intracellular $L$. donovani $(14,15,17)$, IFN- $\gamma$ also enhances the capacity of these cells to accumulate Pentostam (21) and acts synergistically with Pentostam in the intact euthymic animal (21). IL-2 does not directly activate the macrophage (30), but may augment the effects of cytotoxic $T$ cells and natural killer cells $(27,31)$, and in addition, induce the secretion of IFN- $\gamma$ (32-35). In the presence of responsive natural killer cells (35-37), for example, the induction of IFN- $\gamma$ may explain the observation that rIL-2 enhanced the efficacy of Pentostam in nude mice.

Together, these findings serve to reemphasize that, in addition to a microbicidal drug, the successful host response to chemotherapy in systemic intracellular infections such as visceral leishmaniasis requires the active participation of $T$ cells and may involve one or more of their secretory products. Other chemotherapeutic agents in addition to Pentostam may similarly act in concert with the host immune response (38). The type of analysis presented here may also prove useful in defining the immunologic determinants of the effective response to antibiotic drug treatment for other intracellular infections, and lead to new immunochemotherapeutic antimicrobial regimens for the $\mathrm{T}$ cell-deficient patient.

\section{Acknowledgments}

We are grateful to Drs. Bruce Devens (Hoffman-LaRoche) and Michael Shepard (Genentech) for providing the rIL-2 and rIFN- $\gamma$, respectively.

This study was supported by research grants from the National Institutes of Health (AI-16963, CA-43059, AI-24854), Eli Lilly Research Laboratories, and Genentech, Inc.

\section{References}

1. Ma, D. D. F., A. J. Concannon, and J. Hayes. 1979. Fatal leishmaniasis in renal transplant patient. Lancet. 2:311-312.

2. Wallis, P. J. W., and C. J. M. Clark. 1983. Visceral leishmaniasis complicating systemic lupus erythematosus. Ann. Rheum. Dis. 42:201-202.

3. Badaro, R., H. Rocha, E. M. Carvallo, A. C. Queiroz, and T. C. Jones. 1986. Leishmania donovani: an opportunistic microbe associated with progressive disease in three immunocompromised patients. Lancet. 1:647-649.
4. Lamas, S., L. Orte, F. Parras, J. Garcia, R. Matesanz, and J. Ortuno. 1987. Non-fatal leishmaniasis in a renal transplant recipient. Nephron. 45:71.

5. Senaldi G., G. Cadeo, G. Carnevale, G. diPerri, and G. Carosi. 1986. Visceral leishmaniasis as an opportunistic infection. Lancet. 1:1094.

6. Fernandez-Guerrero, M. L., J. M. Aguado, L. Buzon, C. Barros, C. Montalban, T. Martin, and E. Bouza. 1987. Visceral leishmaniasis in immunocompromised hosts. Am. J. Med. 83:1098-1102.

7. Yebra, M., J. Segovia, L. Manzano, J. A. Vargas, L. B. deQuiros, and J. Alvar. 1988. Disseminated-to-skin kala-azar and the acquired immunodeficiency syndrome. Ann. Intern. Med. 108:490-491.

8. Pearson, R. D., D. A. Wheeler, L. H. Harrison, and H. D. Kay. 1983. The immunobiology of leishmaniasis. Rev. Infect. Dis. 5:9071007.

9. Murray, H. W., J. J. Stern, K. Welte, B. Y. Rubin, S. M. Carriero, and C. F. Nathan. 1987. Experimental visceral leishmaniasis: production of interleukin 2 and interferon- $\gamma$, tissue immune reaction, and response to treatment with interleukin 2 and interferon- $\gamma . J$. Immunol. 138:2290-2297.

10. Stern, J., M. Oca, B. Y. Rubin, S. Anderson, and H. W. Mur-

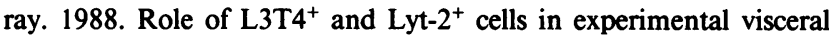
leishmaniasis. J. Immunol. 140:3971-3977.

11. Murray, H. W. 1988. Interferon-gamma, the activated macrophage and host defense against microbial challenge. Ann. Intern. Med. 108:595-608.

12. Murray, H. W., H. Masur, and J. S. Keithly. 1982. Cell-mediated immune response in experimental visceral leishmaniasis. I. Correlation between resistance to $L$. donovani and lymphokine-generating capacity. J. Immunol. 129:344-350.

13. Murray, H. W., and D. M. Cartelli. 1983. Killing of intracellular Leishmania donovani by human mononuclear phagocytes: evidence for oxygen-dependent and -independent leishmanicidal activity. J. Clin. Invest. 72:32-44.

14. Murray, H. W., B. Y. Rubin, and C. D. Rothermel. 1983. Killing of intracellular Leishmania donovani by lymphokine-stimulated human mononuclear phagocytes. Evidence that interferon- $\gamma$ is the activating lymphokine. J. Clin. Invest. 72:1506-1510.

15. Hoover, D. L., C. A. Nacy, and M. S. Meltzer. 1985. Human monocyte activation for cytotoxicity against intracellular Leishmania donovani amastigotes: induction of microbicidal activity by interferon-gamma. Cell. Immunol. 94:500-511.

16. Hoover, D. L., D. S. Finbloom, R. M. Crawford, C. A. Nacy, M. Gilbreath, and M. S. Meltzer. 1986. A lymphokine distinct from interferon- $\gamma$ that activates human monocytes to kill Leishmania donovani in vitro. J. Immunol. 136:1329-1333.

17. Murray, H. W., G. W. Spitalny, and C. F. Nathan. 1985. Activation of mouse peritoneal macrophages in vitro and in vivo by interferon-gamma. J. Immunol. 134:1619-1622.

18. Carvalho, E. M., R. Badaro, S. G. Reed, T. C. Jones, W. D. Johnson, Jr. 1985. Absence of gamma interferon and interleukin 2 production during active visceral leishmaniasis. J. Clin. Invest. 76:2066-2069.

19. Sacks, D. L., S. L. Lal, S. N. Shrivastava, J. Blackwell, and F. A. Neva. 1987. An analysis of T cell responsiveness in Indian kala-azar. $J$. Immunol. 138:908-913.

20. Berman, J. D., J. D. Chulay, L. D. Hendricks, and C. N. Oster. 1982. Susceptibility of clinically sensitive and resistant Leishmania to pentavalent antimony in vitro. Am. J. Trop. Med. Hyg. 31:459-465.

21. Murray, H. W., J. D. Berman, and S. D. Wright. 1988. Immunochemotherapy for intracellular Leishmania donovani infection: interferon- $\gamma$ plus pentavalent antimony. J. Infect. Dis. 157:973-978.

22. Ho, M., D. K. Koech, D. W. Iha, and A. D. M. Bryceson. 1983. Immunosuppression in Kenyan visceral leishmaniasis. Clin. Exp. Immunol. 51:207-215.

23. Manson-Bahr, P. E. C. 1959. East African kala-azar with special reference to the pathology, prophylaxis, and treatment. Trans. Soc. Trop. Med. Hyg. 53:123-126. 
24. Chulay, J. D., S. M. Blatt, R. Muigai, M. Ho, G. Gachihi, J. B. O. Were, C. Chunge, and A. D. M. Bryceson. 1983. A comparison of three dosage regimens of sodium stibogluconate in the treatment of visceral leishmaniasis in Kenya. J. Infect. Dis. 148:148-155.

25. Murray, H. W., S. M. Carriero, and S. M. Donelly. 1986. Presence of a macrophage-mediated suppressor cell mechanism during cell-mediated immune response in experimental visceral leishmaniasis. Infect. Immun. 54:487-493.

26. McElrath, J., H. W. Murray, and Z. A. Cohn. 1988. Dynamics of granuloma formation in experimental visceral leishmaniasis. J. Exp. Med. 167:1927-1937.

27. Hefeneider, S. H., P. J. Conlon, C. S. Henney, and S. Gillis. 1983. In vivo interleukin 2 administration augments the generation of alloreactive cytotoric $T$ lymphocytes and resident natural killer cells. $J$. Immunol. 130:222-227.

28. Kaufmann, S. H., E. Hug, and G. deLibero. 1986. Listeria monocytogenes-reactive $\mathrm{T}$ cell clones with cytolytic activity against infected target cells. J. Exp. Med. 164:363-368.

29. Murray, H. W., M. Oca, and A. Granger. 1988. Continuous vs. intermittent treatment with gamma interferon or Pentostam for experimental visceral leishmaniasis. Clin. Res. 36:581. (Abstr.)

30. Nathan, C. F., T. J. Prendergast, M. E. Wiebe, E. R. Stanley, E. Platzer, H. G. Remold, K. Welte, B. Y. Rubin, and H. W. Murray. 1984. Activation of human macrophages. Comparison of other cytokines with interferon- $\gamma . J$. Exp. Med. 160:600-605.
31. Sharma, S. D., J. M. Hofflin, and J. S. Remington. 1985: In vivo recombinant interleukin 2 administration enhances survival against a lethal challenge with Toxoplasma gondii. J. Immunol. 135:4160-4163.

32. Murray, H. W., K. Welte, J. L. Jacobs, B. Y. Rubin, R. Mertelsmann, and R. B. Roberts. 1985. Production of and in vitro response to interleukin 2 in the acquired immunodeficiency syndrome. J. Clin. Invest. 76:1959-1964.

33. Kelly, C. D., K. Welte, and H. W. Murray. 1987. Antigen-induced human interferon- $\gamma$ production: differential dependence on interleukin 2 and its receptor. J. Immunol. 139:2325-2329.

34. Vilcek, J., D. Henriksen-Destefano, D. Siegel, A. Klion, R. J. Robb, and J. Le. 1985. Regulation of IFN- $\gamma$ induction in human peripheral blood cells by exogenous and endogenously produced interleukin 2. J. Immunol. 135:1851-1857.

35. Murray, H. W., J. DePamphilis, R. T. Schooley, and M. S. Hirsch. 1988. Circulating interferon-gamma in AIDS patients treated with interleukin 2 (letter). N. Engl. J. Med. 318:1538-1539.

36. Handa K., R. Suzuki, H. Matsui, Y. Shimizu, and K. Kumagai. 1983. Natural killer (NK) cells as a responder to interleukin 2 (IL 2). II. IL 2-induced interferon- $\gamma$ production. J. Immunol. 130:988-992.

37. Bancroft, G. J., R. D. Schreiber, G. C. Bosma, M. J. Bosma, and E. R. Unanue. 1987. A T cell-independent mechanism of macrophage activation by interferon- $\gamma$. J. Immunol. 139:1104-1107.

38. Targett, G. A. T. 1985. Chemotherapy and the immune response in parasitic infections. Parasitology. 90:661-673. 